\title{
Thermodynamic Study of Phase Equilibria in the Ni-Fe-B System
}

\author{
Tatsuya Tokunaga ${ }^{1}$, Hiroshi Ohtani ${ }^{1,2}$ and Mitsuhiro Hasebe ${ }^{1,2}$ \\ ${ }^{1}$ Core Research for Evolutional Science and Technology (CREST), Japan Science and Technology Agency, \\ Kitakyushu 804-8550, Japan \\ ${ }^{2}$ Department of Materials Science and Engineering, Kyushu Institute of Technology, Kitakyushu 804-8550, Japan
}

\begin{abstract}
The phase equilibria in the Ni-Fe-B ternary system have been studied experimentally and using thermodynamic calculations. The Gibbs energy of the individual phases was described by the regular solution approximation and the two-sublattice model. The thermodynamic parameters for each phase were evaluated using the experimental data on phase boundaries obtained from differential scanning calorimetry (DSC) and other available literature data. The evaluated parameters enabled us to obtain reproducible calculations of the isothermal section diagrams. The calculated isopleth at the $26 \mathrm{~mol} \% \mathrm{~B}$ section agreed with the DSC data obtained in this study, whereas the calculated liquidus and solidus temperatures were higher than the reported values at the $\mathrm{Ni}_{2} \mathrm{~B}-\mathrm{Fe}_{2} \mathrm{~B}$ pseudo-binary section.
\end{abstract}

(Received December 21, 2004; Accepted March 3, 2005; Published June 15, 2005)

Keywords: phase equilibria, nickel-iron-boron, thermodynamic analysis, borides, calculation of phase diagrams

\section{Introduction}

A thermodynamic description for the $\mathrm{Ni}-\mathrm{Fe}-\mathrm{B}$ ternary system is of interest in several fields of materials engineering. For example, boron is a commonly known alloying element that enhances the hardenability of steels, and forms Ni- or Febased amorphous alloys. Recently, the effect of boron addition on the hardenability, mechanical properties, and workability of steels, stainless steels, and heat-resistant steels has been reviewed. ${ }^{1)}$ In addition, in Ni-based brazing filler metals and Ni-based self-fluxing alloys, boron is added to reduce the melting temperatures and to improve fluidity. Furthermore, metallic composite materials comprised of various transition metal borides have attractive wear- or corrosion-resistant properties. ${ }^{2,3)}$ Therefore, information on the phase equilibria of the $\mathrm{Ni}-\mathrm{Fe}-\mathrm{B}$ ternary system is required to develop a wide variety of B-containing alloys.

The CALculation of PHAse Diagrams (CALPHAD) approach $^{4)}$ provides a powerful tool for obtaining information on physical parameters, such as the amount and composition of constituent phases, and the liquidus and solidus temperatures.

In the present study, a thermodynamic analysis of the $\mathrm{Ni}-$ $\mathrm{Fe}-\mathrm{B}$ ternary system has been carried out by combining the experimental results obtained from differential scanning calorimetry with literature data on the phase relationships.

\section{Experimental Procedures}

The phase boundaries of the $\mathrm{Ni}-\mathrm{Fe}-\mathrm{B}$ ternary system were measured using differential scanning calorimetry (DSC) in the section with $26 \mathrm{~mol} \% \mathrm{~B}$. The starting materials used were $\mathrm{Ni}(99.9 \%), \mathrm{Fe}(99.998 \%)$, and B (99\%) powders. The nominal compositions of the prepared samples are listed in Table 1. The alloys for the DSC measurements were prepared by arc melting cold-pressed pellets, each of about $10 \mathrm{~g}$ in weight, in an argon atmosphere. A titanium button was melted to getter any residual oxygen in the chamber before melting the actual charges. The arc-melted alloys were re-melted under vacuum using an induction heater to ensure sample homogeneity. The as-cast alloys were then encapsulated in transparent quartz tubes under vacuum, and then annealed at $950^{\circ} \mathrm{C}$ for $7 \mathrm{~d}$ before being quenched in water. After the heat treatment, the actual compositions of samples were chemically analyzed. According to the results, the $\mathrm{Ni}$ / Fe ratios obtained by chemical analysis were consistent with the nominal ratios within the experimental uncertainties, whereas the losses of $\mathrm{B}$ were observed. Hence, the alloy compositions were corrected based on the results of chemical analysis. The corrected compositions are listed in Table 1. Thermal analysis was carried out using a Seiko EXSTAR6300 DSC (Seiko Instruments Inc., Chiba, Japan) on cylindrical samples heated and cooled in $\mathrm{Al}_{2} \mathrm{O}_{3}$ crucibles at a rate of $5^{\circ} \mathrm{C} / \mathrm{min}$ under flowing purified argon using an $\alpha$ -

Table 1 Alloy compositions, experimental results from DSC on heating, and the calculated liquidus temperatures of Ni-Fe-B ternary alloys.

\begin{tabular}{|c|c|c|c|c|c|c|c|c|c|}
\hline \multicolumn{6}{|c|}{ Alloy composition (mol\%) } & & & & \multirow{3}{*}{$\begin{array}{l}\text { Calculated liquidus } \\
\text { temperature }\left({ }^{\circ} \mathrm{C}\right)\end{array}$} \\
\hline \multicolumn{3}{|c|}{ Nominal } & \multicolumn{3}{|c|}{ Corrected } & \multicolumn{3}{|c|}{ Peak temperature $\left({ }^{\circ} \mathrm{C}\right)$} & \\
\hline $\mathrm{Ni}$ & $\mathrm{Fe}$ & B & $\mathrm{Ni}$ & $\mathrm{Fe}$ & B & & & & \\
\hline 60 & 12 & 28 & 62.2 & 11.4 & 26.4 & 1072 & 1096 & 1128 & 1137 \\
\hline 50 & 22 & 28 & 52.0 & 23.2 & 24.8 & 1056 & 1095 & 1201 & 1192 \\
\hline 40 & 32 & 28 & 40.8 & 34.3 & 24.9 & 1055 & 1090 & 1268 & 1260 \\
\hline 20 & 52 & 28 & 17.4 & 57.4 & 25.2 & 1084 & 1088 & 1345 & 1350 \\
\hline
\end{tabular}


$\mathrm{Al}_{2} \mathrm{O}_{3}$ reference standard. The peak temperature values during heating were adopted in our thermodynamic analysis to avoid any experimental errors caused by supercooling. The peak temperatures during heating are shown in Table 1.

\section{Thermodynamic Description}

In the present modeling of the $\mathrm{Ni}-\mathrm{Fe}-\mathrm{B}$ system, the thermodynamic parameters in the $\mathrm{Ni}-\mathrm{Fe}$ and $\mathrm{Fe}-\mathrm{B}$ systems were taken from Dinsdale and $\mathrm{Chart}^{5)}$ and Pan, ${ }^{6)}$ respectively. For the Ni-B system, the parameters assessed by Tokunaga et al. ${ }^{7)}$ based on the results of Campbell and Kattner, ${ }^{8)}$ were adopted. In the latter two modelings, boron was treated as a substitutional element in the bcc or fcc phases, and the solubility of $\mathrm{Ni}$ or $\mathrm{Fe}$ in $\beta$-rhombohedral $\mathrm{B}$ was not taken into account because of the negligible solubility.

For the liquid and terminal solid solution phases, the Gibbs energy was expressed using the regular solution approximation as follows:

$$
\begin{aligned}
G_{\mathrm{m}}^{\phi}= & x_{\mathrm{B}}^{\circ} G_{\mathrm{B}}^{\phi}+x_{\mathrm{Fe}}{ }^{\circ} G_{\mathrm{Fe}}^{\phi}+x_{\mathrm{Ni}}{ }^{\circ} G_{\mathrm{Ni}}^{\phi} \\
& +R T\left(x_{\mathrm{B}} \ln x_{\mathrm{B}}+x_{\mathrm{Fe}} \ln x_{\mathrm{Fe}}+x_{\mathrm{Ni}} \ln x_{\mathrm{Ni}}\right)
\end{aligned}
$$

$$
\begin{aligned}
& +x_{\mathrm{B}} x_{\mathrm{Fe}} L_{\mathrm{B}, \mathrm{Fe}}^{\phi}+x_{\mathrm{Fe}} x_{\mathrm{Ni}} L_{\mathrm{Fe}, \mathrm{Ni}}^{\phi}+x_{\mathrm{B}} x_{\mathrm{Ni}} L_{\mathrm{B}, \mathrm{Ni}}^{\phi} \\
& +x_{\mathrm{B}} x_{\mathrm{Fe}} x_{\mathrm{Ni}} L_{\mathrm{B}, \mathrm{Fe}, \mathrm{Ni}}^{\phi},
\end{aligned}
$$

where ${ }^{\circ} G_{i}^{\phi}$ is the lattice stability, and denotes the Gibbs energy of element $i$ in the $\phi$ phase state. The descriptions of the lattice stability parameters were taken from the Scientific Group Thermodata Europe (SGTE) data file, ${ }^{9)}$ where the Gibbs energy of each element is defined with respect to its stable state at $25^{\circ} \mathrm{C}$ and $101325 \mathrm{~Pa}$, and are listed in Table 2 . $R$ is the gas constant, and $x_{\mathrm{B}}, x_{\mathrm{Fe}}$ and $x_{\mathrm{Ni}}$ denote the mole fractions of $\mathrm{B}, \mathrm{Fe}$, and $\mathrm{Ni}$, respectively. The parameter $L_{i, j}^{\phi}$ denotes the interaction energy between elements $i$ and $j$ in the $\phi$ phase. The term $L_{\mathrm{B}, \mathrm{Fe}, \mathrm{Ni}}^{\phi}$ is the ternary interaction parameter between elements $\mathrm{B}, \mathrm{Fe}$, and $\mathrm{Ni}$. The composition dependency of the interaction parameters $L_{i, j}^{\phi}$ and $L_{\mathrm{B}, \mathrm{Fe}, \mathrm{Ni}}^{\phi}$ is expressed by eqs. (2) and (3), respectively.

$$
\begin{aligned}
L_{i, j}^{\phi} & =\sum_{n}\left(x_{i}-x_{j}\right)^{n} \cdot{ }^{n} L_{i, j}^{\phi}, \\
L_{\mathrm{B}, \mathrm{Fe}, \mathrm{Ni}}^{\phi} & =x_{\mathrm{B}} \cdot{ }^{0} L_{\mathrm{B}, \mathrm{Fe}, \mathrm{Ni}}^{\phi}+x_{\mathrm{Fe}} \cdot{ }^{1} L_{\mathrm{B}, \mathrm{Fe}, \mathrm{Ni}}^{\phi}+x_{\mathrm{Ni}} \cdot{ }^{2} L_{\mathrm{B}, \mathrm{Fe}, \mathrm{Ni}}^{\phi} \cdot
\end{aligned}
$$

Table 2 The lattice stability parameters for $\mathrm{Ni}, \mathrm{Fe}$, and B.

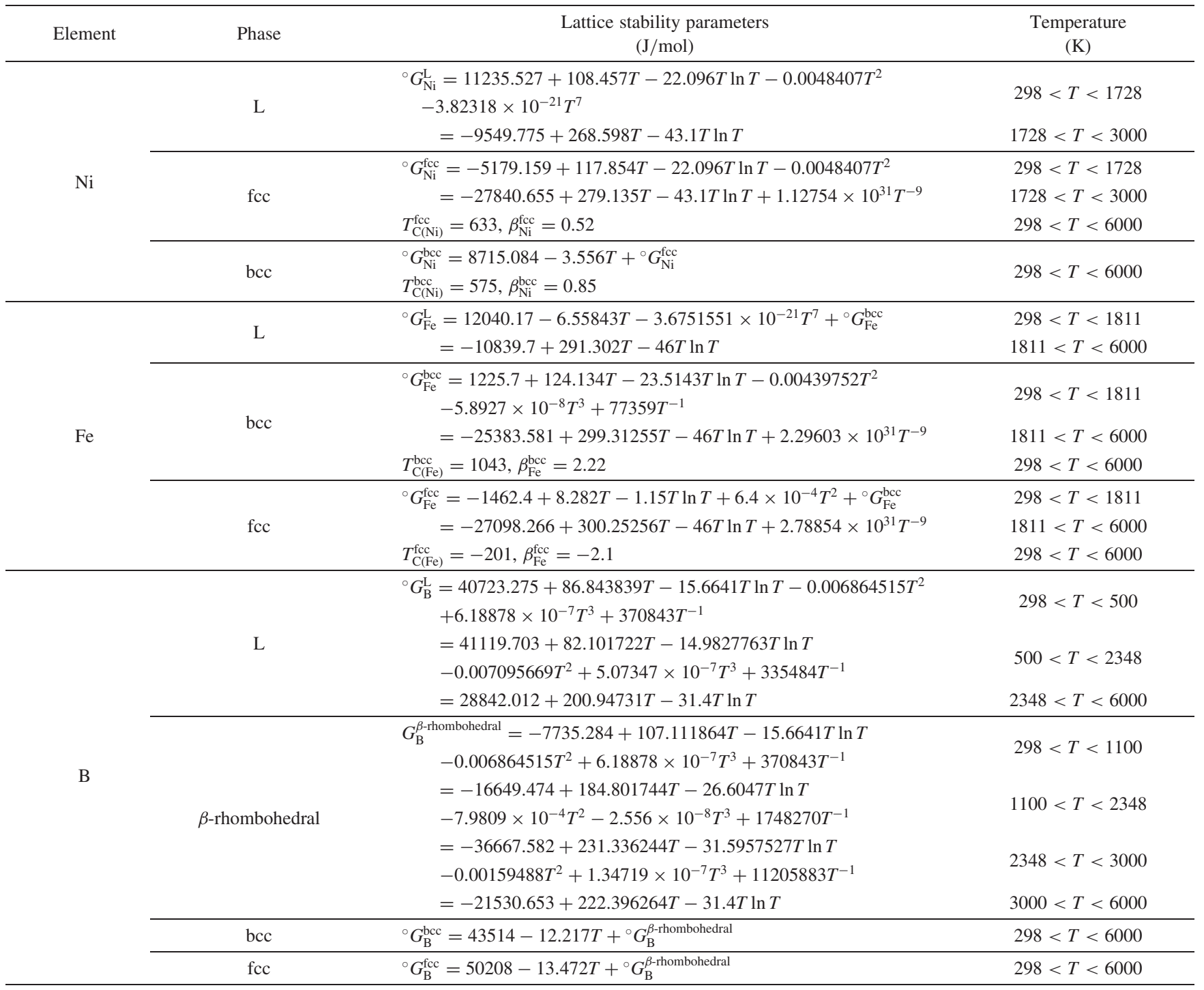


The Gibbs energy contributions due to the ferromagnetic ordering of a phase, such as the bcc phase, were described using the model of Hillert and Jarl ${ }^{10)}$

$$
{ }^{\mathrm{mag}} G_{\mathrm{m}}^{\phi}=R T \ln \left(\beta^{\phi}+1\right) f(\tau),
$$

where ${ }^{\mathrm{mag}} G_{\mathrm{m}}^{\phi}$ is the Gibbs energy of magnetic ordering, $\beta^{\phi}$ is the average magnetic moment per atom in the $\phi$ phase (expressed in Bohr magnetons), and $f(\tau)$ is a polynomial function of $\tau$. The term $\tau$ is defined as $T / T_{\mathrm{C}}^{\phi}$, where $T_{\mathrm{C}}^{\phi}$ is the critical temperature of the magnetic transition in the $\phi$ phase. Both $\beta^{\phi}$ and $T_{\mathrm{C}}^{\phi}$ can be concentration-dependent, and are represented by an equation similar to that of eq. (2).

Except for $\mathrm{Ni}_{3} \mathrm{~B}, \mathrm{Ni}_{2} \mathrm{~B}, \mathrm{Fe}_{2} \mathrm{~B}, \mathrm{FeB}$, and $\mathrm{NiB}$, the other binary compound phases were treated as being pure binary phases based on the experimental results, as described in the next section. Borides that can dissolve a different metallic element are considered to be stoichiometric with respect to the boron content, and the Gibbs energy of $\varphi$ boride having the formula $\mathrm{M}_{m} \mathrm{~B}_{n}$ (where $\mathrm{M}$ represents $\mathrm{Fe}$ or $\mathrm{Ni}$ ) was described using the two-sublattice model, ${ }^{11)}$ assuming one sublattice was occupied by $\mathrm{Fe}$ and $\mathrm{Ni}$ atoms, and the other sublattice was occupied by $\mathrm{B}$ atoms as follows:

$$
\begin{aligned}
G= & y_{\mathrm{Fe}} \cdot{ }^{\circ} G_{\mathrm{Fe}: \mathrm{B}}^{\varphi}+y_{\mathrm{Ni}} \cdot{ }^{\circ} G_{\mathrm{Ni}: \mathrm{B}}^{\varphi} \\
& +m R T\left(y_{\mathrm{Fe}} \ln y_{\mathrm{Fe}}+y_{\mathrm{Ni}} \ln y_{\mathrm{Ni}}\right)+y_{\mathrm{Fe}} y_{\mathrm{Ni}} \cdot L_{\mathrm{Fe}, \mathrm{Ni}: \mathrm{B}}^{\varphi},
\end{aligned}
$$

where ${ }^{\circ} G_{\mathrm{Fe}: \mathrm{B}}^{\varphi}$ and ${ }^{\circ} G_{\mathrm{Ni}: \mathrm{B}}^{\varphi}$ represent the Gibbs energies of pure $\mathrm{Fe}_{m} \mathrm{~B}_{n}$ and $\mathrm{Ni}_{m} \mathrm{~B}_{n}$, respectively. The term $L_{\mathrm{Fe}, \mathrm{Ni}: \mathrm{B}}^{\varphi}$ is the interaction parameter between $\mathrm{Fe}$ and $\mathrm{Ni}$ in the metallic sublattice, and is described by an equation similar to eq. (2). The term $y_{i}$ is the site fraction of element $i$ in the metallic sublattice.

For the pure binary compound phases, $\mathrm{M}_{a} \mathrm{~B}_{b}$, the Gibbs energy per mole of atoms was expressed using following equation:

$$
G_{\mathrm{m}}^{\mathrm{M}_{a} \mathrm{~B}_{b}}=\frac{a}{a+b} \cdot{ }^{\circ} G_{\mathrm{M}}^{\mathrm{ref}}+\frac{b}{a+b} \cdot{ }^{\circ} G_{\mathrm{B}}^{\beta \text {-rhombohedral }}+\Delta G_{\mathrm{M}_{a} \mathrm{~B}_{b}}^{f},
$$

where ${ }^{\circ} G_{\mathrm{M}}^{\mathrm{ref}}$ denotes the reference state of the metallic elements. The term $\Delta G_{\mathrm{M}_{a} \mathrm{~B}_{b}}^{f}$ is the Gibbs energy of formation per mole of atoms of the boride. It can be expressed using the following equation:

$$
\Delta G_{\mathrm{M}_{a} \mathrm{~B}_{b}}^{f}=A+B \cdot T .
$$

\section{Thermodynamic Analysis and Calculation of the Phase Diagrams}

In the $\mathrm{Ni}-\mathrm{Fe}-\mathrm{B}$ ternary system, Kaneko et al. ${ }^{12)}$ and Stadelmaier and Pollock ${ }^{13}$ ) have investigated the phase relationships at 700 and $800^{\circ} \mathrm{C}$, respectively, at the $\mathrm{Ni}-\mathrm{Fe}$ side using microscopy and X-ray diffraction techniques, where Kaneko et al. did not identify a stable $\mathrm{Ni}_{3} \mathrm{~B}$ phase in the $\mathrm{Ni}-\mathrm{B}$ system. Kuz'ma and Koval ${ }^{14)}$ have provided the isothermal section diagrams at $800^{\circ} \mathrm{C}$ over the entire composition range using both microscopy and X-ray diffraction. According to the experimental results, ${ }^{12-14)}$ a continuous series of solid solutions is formed between the tetragonal borides $\mathrm{Fe}_{2} \mathrm{~B}$ and $\mathrm{Ni}_{2} \mathrm{~B}$, where both borides have the same crystal structure $\left(\mathrm{CuAl}_{2}\right.$-type). Hereafter, these are denoted as the $\mathrm{M}_{2} \mathrm{~B}$-tetr phase. For the $\mathrm{Ni}_{3} \mathrm{~B}$ phase, the solubility of $\mathrm{Fe}$ reaches about $45 \mathrm{~mol} \% \mathrm{Fe}^{13,14)}$ Although Kuz'ma and Koval ${ }^{14}$ ) could not determined the solubility limit accurately, the $\mathrm{FeB}$ phase dissolves not less than $5 \mathrm{~mol} \% \mathrm{Ni}$, whereas $\mathrm{NiB}$ does not dissolve any appreciable amounts of $\mathrm{Fe}$ (less than $5 \mathrm{~mol} \% \mathrm{Fe}) .{ }^{14)}$ Tavadze et al. ${ }^{15,16)}$ have studied the phase equilibria in the $\mathrm{Fe}_{2} \mathrm{~B}-\mathrm{Ni}_{2} \mathrm{~B}$ section of the pseudo-binary system. They also confirmed the existence of a complete solid solution existing between both borides, and they provided the liquidus and solidus temperatures in this pseudo-binary system. Gianoglio and Badini ${ }^{17)}$ have studied the variation in lattice parameter at $800^{\circ} \mathrm{C}$ at the $\mathrm{Fe}_{2} \mathrm{~B}-\mathrm{Ni}_{2} \mathrm{~B}$ and $\mathrm{FeB}-\mathrm{NiB}$ sections. They reported that a complete solid solution exists between the $\mathrm{Fe}_{2} \mathrm{~B}$ and $\mathrm{Ni}_{2} \mathrm{~B}$, and that $\mathrm{Ni}$ atoms can substitute for $\mathrm{Fe}$ in the $\mathrm{FeB}$ phase up to $70 \mathrm{~mol} \%$, whereas $\mathrm{Fe}$ atoms can substitute for $\mathrm{Ni}$ in the $\mathrm{NiB}$ phase up to $15 \mathrm{~mol} \%$. The results on the solubility of metallic elements in both the $\mathrm{FeB}$ and $\mathrm{NiB}$ phases are different from those obtained by Stadelmaier and Pollock ${ }^{13)}$ and Kuz'ma and Koval. ${ }^{14)}$ It seems that these discrepancies are due to differences in the duration of a heat treatment, as Gianoglio and Badini heated the alloys to $800^{\circ} \mathrm{C}$ for $20 \mathrm{~h}$ at most, while on the other hand, Kuz'ma and Koval annealed their samples at $800^{\circ} \mathrm{C}$ for $600 \mathrm{~h}$. Therefore, the experimental diagram described by Gianoglio and Badini may not have reached equilibrium state. Loo and Beek ${ }^{18}$ ) have reported on the isothermal section diagram at $925^{\circ} \mathrm{C}$ at the $\mathrm{Ni}-\mathrm{Fe}$ side, and their results are almost the same as those of Stadelmaier and Pollock, ${ }^{13)}$ and Kuz'ma and Koval. ${ }^{14)}$

Although no stable ternary compound phase has been reported in the $\mathrm{Ni}-\mathrm{Fe}-\mathrm{B}$ ternary system, a metastable $\mathrm{Ni}_{20} \mathrm{Fe}_{3} \mathrm{~B}_{6}$ phase with a $\mathrm{Cr}_{23} \mathrm{C}_{6}$-type structure has been reported. ${ }^{13)}$ There are no experimental data available on the thermodynamic properties of the $\mathrm{Ni}-\mathrm{Fe}-\mathrm{B}$ system.

In the present study, the thermodynamic parameters of the $\mathrm{Ni}-\mathrm{Fe}-\mathrm{B}$ system have been evaluated based on the experimental data of Stadelmaier and Pollock, ${ }^{13}$ Kuz'ma and Koval, ${ }^{14)}$ and Loo and Beek ${ }^{18)}$ as well as the present DSC results. It is noted that, since we could not obtain ternary parameters to fit to the experimental data of Tavadze et al. ${ }^{15,16)}$ with other experimental data as well as the DSC data in our preliminary analysis, the data of Tavadze et al. were not adopted finally. Because of the lack of experimental information on the phase stability of the nonstable NiB phase with the same structure as that of the stable FeB phase, the parameter ${ }^{\circ} G_{\mathrm{Ni} \text { B B }}^{\mathrm{FeB}}$ was determined in accordance with the following equation:

$$
{ }^{\circ} G_{\mathrm{Ni}: \mathrm{B}}^{\mathrm{FeB}}-{ }^{\circ} G_{\mathrm{Ni}: \mathrm{B}}^{\mathrm{NiB}}=E_{\text {total }}^{\mathrm{FeB}(\mathrm{Ni}: \mathrm{B})}-E_{\text {total }}^{\mathrm{NiB}(\mathrm{Ni}: \mathrm{B})},
$$

where $E_{\text {total }}^{\mathrm{FeB}(\mathrm{Ni}: \mathrm{B})}$ and $E_{\text {total }}^{\mathrm{NiB}(\mathrm{Ni}) \mathrm{B})}$ represent the total energies of the nonstable $\mathrm{NiB}$ phase with the same structure as that of the stable FeB phase and the stable NiB phase, respectively. The total energies were obtained from $a b$ initio energetic calculations using the WIEN2k software package, ${ }^{19}$ ) based on the Full Potential Linearized Augmented Plane Wave (FLAPW) method within the generalized gradient approximation (GGA), ${ }^{20)}$ and calculations of the total energy as a function of the cell volume were performed around the equilibrium cell volumes. Since there is no information 
available on the atomic positions for both the stable and nonstable $\mathrm{NiB}$ phases, both phases referred to the atomic positions of their prototype structures, $\mathrm{CrB}$ (Pearson Symbol $o C 8$, Space Group Cmcm) and FeB (Pearson Symbol $t$ I12, Space Group $I 4 / \mathrm{mcm}),{ }^{21)}$ respectively. In our calculations, we assumed muffin-tin radii of 2.0 a.u. $(0.106 \mathrm{~nm})$ for $\mathrm{Ni}$, and 1.4 a.u. $(0.074 \mathrm{~nm})$ for $\mathrm{B}$, and the value of $R K_{\max }$ was fixed at 6.26 for B atom, which almost corresponds to the cut-off energy of $20 \mathrm{Ry}$. It is noteworthy that the parameters ${ }^{\circ} G_{\mathrm{Fe}: \mathrm{B}}^{\mathrm{Ni} \mathrm{B}}$ and ${ }^{\circ} G_{\mathrm{Fe}: \mathrm{B}}^{\mathrm{NiB}}$ were taken from the data of the $\mathrm{Fe}-\mathrm{B}-\mathrm{C}-\mathrm{Cr}-\mathrm{Ti}$ system obtained by Furukawa. ${ }^{22}$ The thermodynamic parameters obtained for the $\mathrm{Ni}-\mathrm{Fe}-\mathrm{B}$ ternary system are listed in Table 3.

The calculated isothermal section diagrams at 800 and $925^{\circ} \mathrm{C}$ are shown in Figs. 1 and 2, respectively, together with the experimental isothermal sections. ${ }^{14,18)}$ The experimental isothermal section of Kuz'ma and Koval ${ }^{14)}$ includes $\mathrm{NiB}_{6}$. However, this phase is not reported as being a stable phase. ${ }^{23)}$ In the three-phase equilibria occurring between the fcc, $\mathrm{Ni}_{3} \mathrm{~B}$, and $\mathrm{M}_{2} \mathrm{~B}$ _tetr phases at both 800 and $925^{\circ} \mathrm{C}$, the calculated $\mathrm{Fe}$ content in the $\mathrm{M}_{2} \mathrm{~B}_{-}$tetr phase was lower than that in the results of Kuz'ma and Koval ${ }^{14)}$ and Loo and Beek. ${ }^{18)}$ In addition, for the tie triangle between the $\mathrm{NiB}, m-\mathrm{Ni}_{4} \mathrm{~B}_{3}$, and $\mathrm{M}_{2} \mathrm{~B}_{-}$tetr phases, the calculated $\mathrm{Fe}$ content in the $\mathrm{M}_{2} \mathrm{~B}_{-}$tetr phase was higher than that of Kuz'ma and Koval, ${ }^{14)}$ where this tie triangle was presented as a tentative construction. Although there are several discrepancies in the equilibrium compositions, the calculated results reproduce the exper-

Table 3 The thermodynamic parameters in the Ni-Fe-B ternary system.

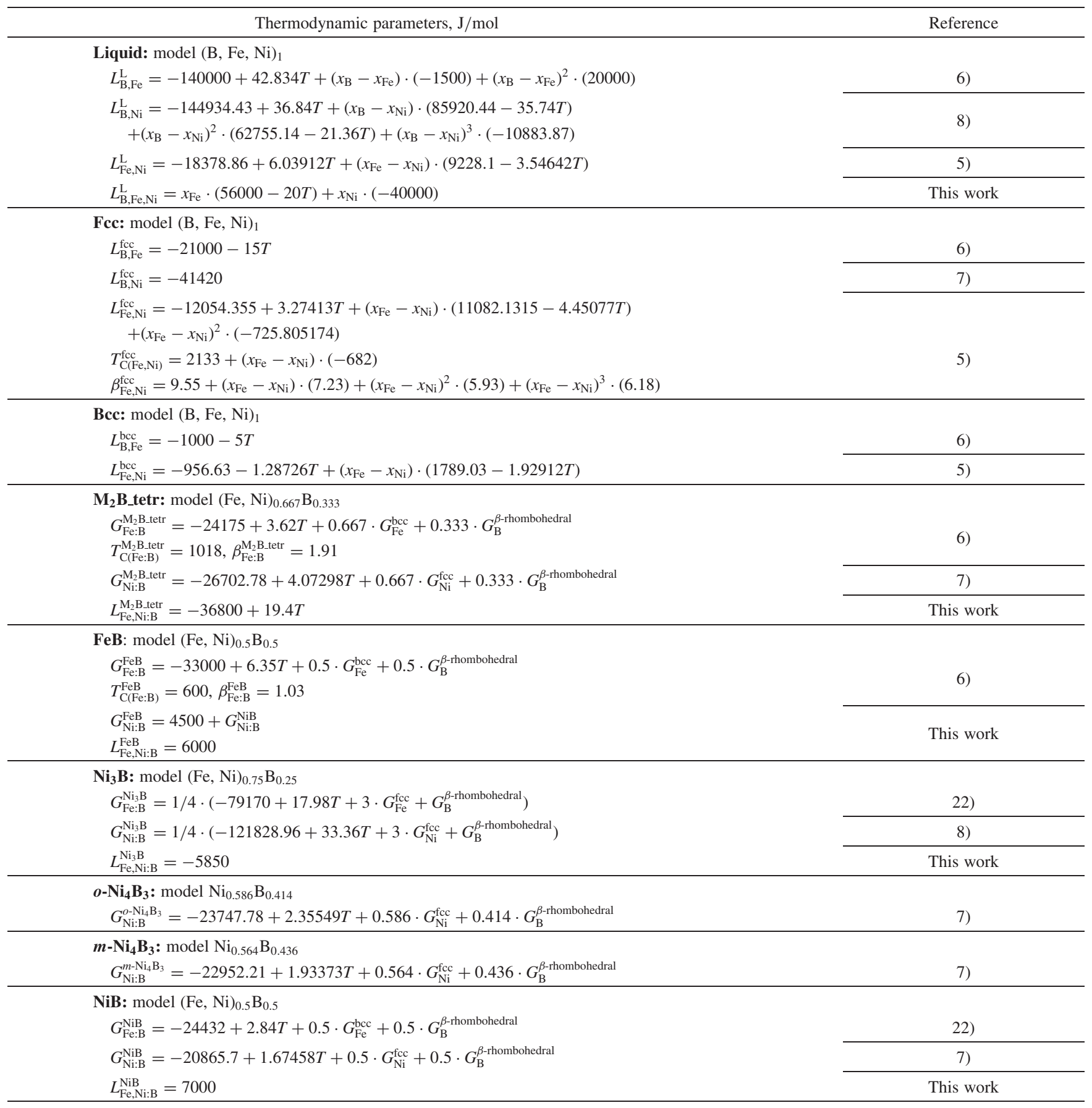


(a)

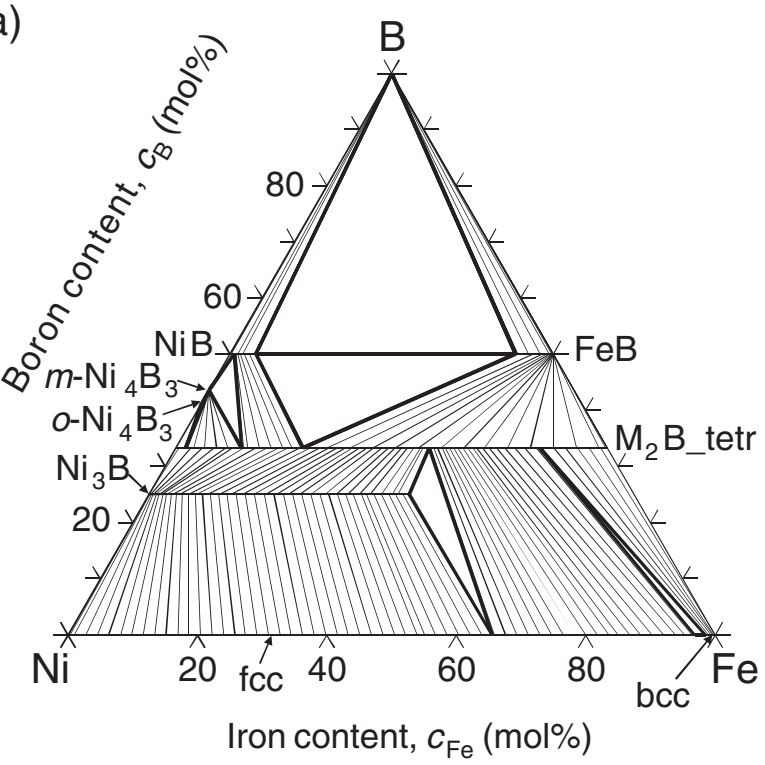

(b)

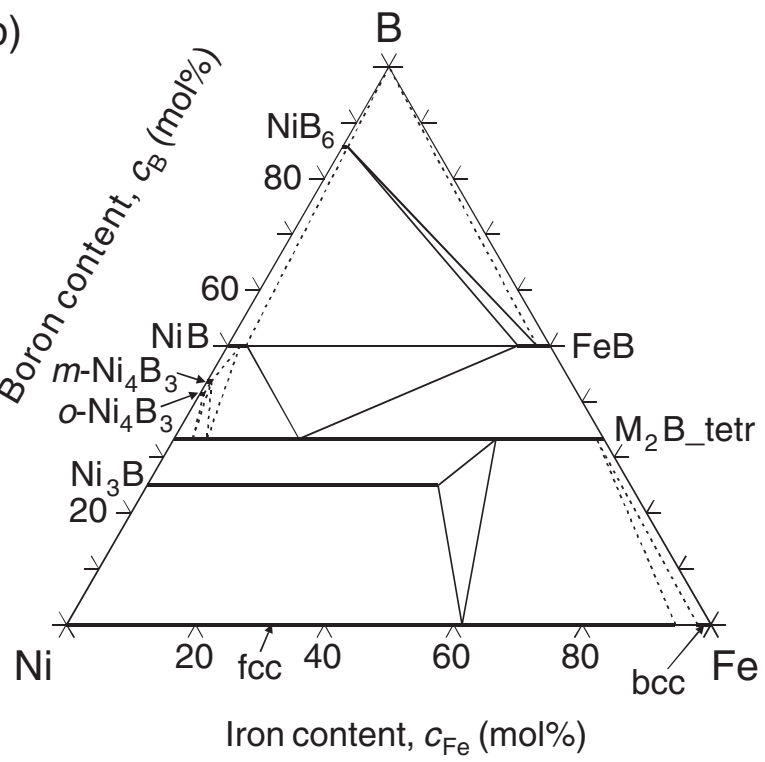

Fig. 1 (a) Calculated and (b) experimental isothermal sections of the $\mathrm{Ni}-$ $\mathrm{Fe}-\mathrm{B}$ system at $800^{\circ} \mathrm{C}$.

imental phase relationships satisfactorily.

Figure 3(a) shows the calculated isopleth at the $26 \mathrm{~mol} \% \mathrm{~B}$ section together with the experimental data obtained from DSC measurements for comparison with the calculated phase boundaries, where the experimental data are not accurately present in this section, and hence, the data are plotted based on the $\mathrm{Ni} / \mathrm{Fe}$ ratios determined by chemical analysis. The calculated liquidus temperatures for each alloy composition are also shown in Table 1. From such a comparison, the calculated phase boundaries agree well with the experimental results. Figure 3(b) shows the calculated isopleth at the $\mathrm{Ni}_{2} \mathrm{~B}-\mathrm{Fe}_{2} \mathrm{~B}$ pseudo-binary section compared with the experimental liquidus and solidus temperatures. ${ }^{15,16)}$ As regards the liquidus and solidus temperatures, the calculated values are higher than the experimental values. It is noteworthy that the experimental melting temperature of $\mathrm{Ni}_{2} \mathrm{~B}$ is higher than the calculated value by about $100^{\circ} \mathrm{C}$, whereas the experimental melting temperature of $\mathrm{Fe}_{2} \mathrm{~B}$ is lower than the (a)
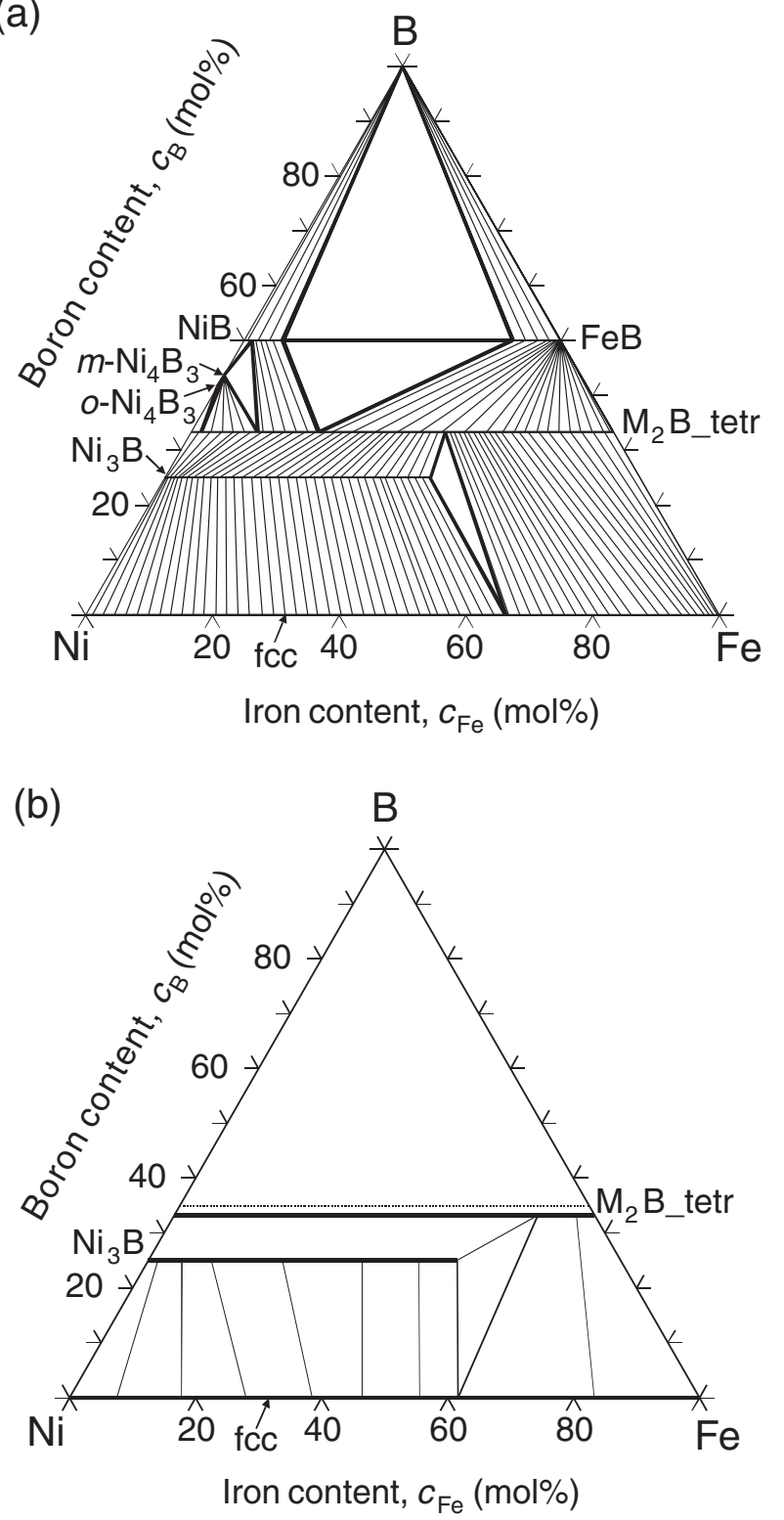

Fig. 2 (a) Calculated and (b) experimental isothermal sections of the Ni$\mathrm{Fe}-\mathrm{B}$ system at $925^{\circ} \mathrm{C}$.

calculated value by about $50^{\circ} \mathrm{C}$. The assessed congruent melting temperature for the $\mathrm{Ni}_{2} \mathrm{~B}$ phase is $1125^{\circ} \mathrm{C},{ }^{23)}$ while on the other hand, the $\mathrm{Fe}_{2} \mathrm{~B}$ phase melts by peritectic reaction at $1389^{\circ} \mathrm{C},{ }^{24)}$ rather than by congruent reaction. Above the peritectic temperature, $\mathrm{FeB}$ coexists with the liquid phase. In the present description, both the congruent melting and the peritectic reaction temperatures are in good agreement with the assessed values within the experimental uncertainties. We could not obtain a copy of the original paper of Tavadze et al. ${ }^{15)}$ cited by Bannykh et al., ${ }^{16)}$ and so its contents are not known. However, by considering the agreement between the calculated and experimental results on the isothermal sections and $26 \mathrm{~mol} \% \mathrm{~B}$ section, the experimental liquidus and solidus temperatures ${ }^{15,16)}$ at the $\mathrm{Ni}_{2} \mathrm{~B}-\mathrm{Fe}_{2} \mathrm{~B}$ pseudobinary section seem to be rather low. Therefore, to clarify these discrepancies, further experimental re-investigation might be needed. 
(a)

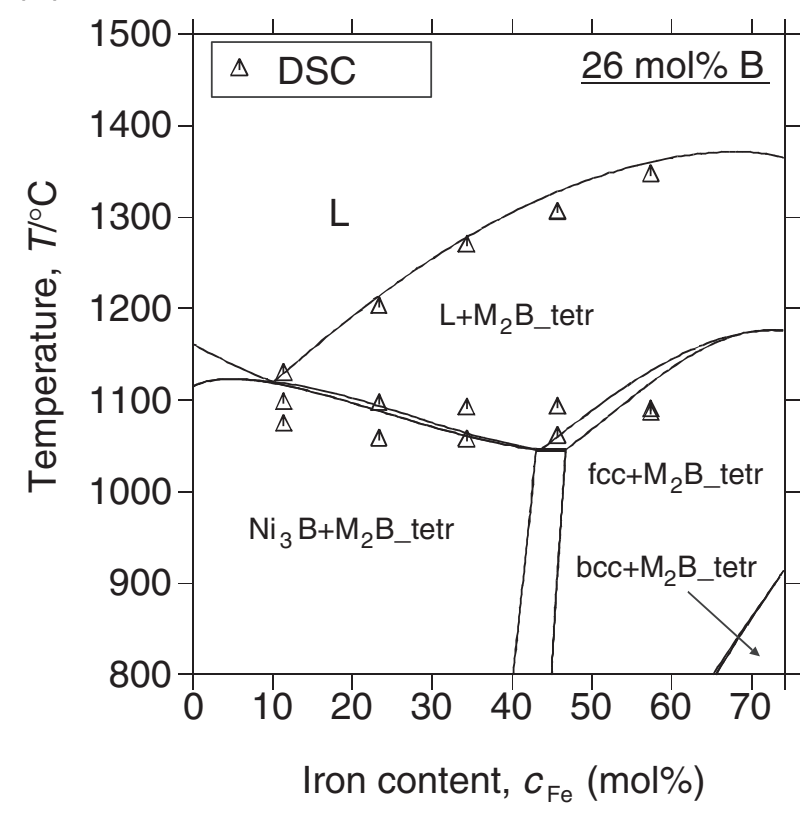

(b)

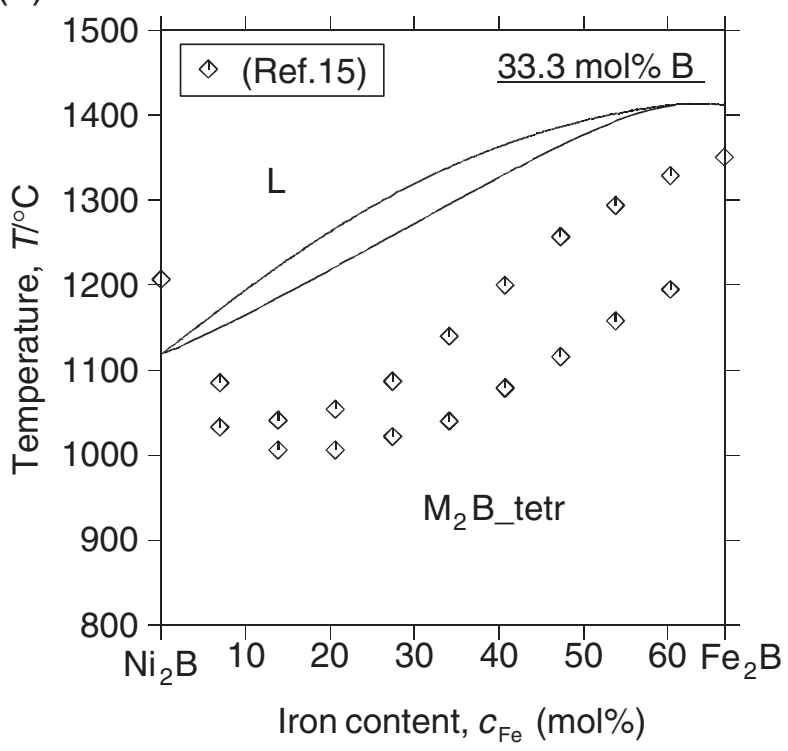

Fig. 3 Calculated isopleths of the Ni-Fe-B system at: (a) the $26 \mathrm{~mol} \% \mathrm{~B}$ and (b) $33.3 \mathrm{~mol} \% \mathrm{~B}$ sections.

\section{Conclusions}

A thermodynamic analysis of the $\mathrm{Ni}-\mathrm{Fe}-\mathrm{B}$ ternary system has been carried out based on the DSC results obtained in this study and available experimental data on the phase equilibria. The results obtained are summarized as follows:

(1) The assessed parameters in the $\mathrm{Ni}-\mathrm{Fe}-\mathrm{B}$ system reproduced the experimental isothermal section diagrams well.

(2) The calculated phase boundaries at the $26 \mathrm{~mol} \% \mathrm{~B}$ section agreed well with the DSC data. In contrast, for the $\mathrm{Ni}_{2} \mathrm{~B}-\mathrm{Fe}_{2} \mathrm{~B}$ pseudo-binary section, there were discrepancies between the calculated and the reported values of the liquidus and solidus temperatures.

\section{Acknowledgements}

The authors express their sincere thanks to Ms. Umegane of Kyushu Institute of Technology for chemical analysis. The authors also acknowledge the use of the Thermo-Calc software program for calculating the equilibrium phase diagrams.

\section{REFERENCES}

1) Research Review on Boron in Steels and Targets for Next Century (in Japanese), (The Iron and Steel Institute of Japan, Tokyo, Japan, 1999).

2) Y. Hashimoto, S. Omori, K. Hidaka and T. Teramoto: J. Jpn. Soc. Powder Powder Metal. 18 (1971) 33-39.

3) T. Watanabe, H. Shimizu and S. Miyagawa: J. Jpn. Soc. Powder Powder Metal. 27 (1980) 137-144.

4) N. Saunders and A. P. Miodownik: CALPHAD, (Pergamon, Elsevier Science Ltd., Oxford, UK, 1998).

5) A. T. Dinsdale and T. G. Chart: In B. Sundman, ed., Scientific Group Thermodata Europe (SGTE) Solution Database Ver. 2, Division of Computational Thermodynamics, Royal Institute of Technology, Stockholm, Sweden, (1994).

6) L.-M. Pan: In B. Sundman, ed., Scientific Group Thermodata Europe (SGTE) Solution Database Ver. 2, Division of Computational Thermodynamics, Royal Institute of Technology, Stockholm, Sweden, (1994).

7) T. Tokunaga, K. Nishio, H. Ohtani and M. Hasebe: Mater. Trans. 44 (2003) 1651-1654.

8) C. E. Campbell and U. R. Kattner: J. Phase Equilib. 20 (1999) 485-496.

9) A. T. Dinsdale: CALPHAD 15 (1991) 317-425.

10) M. Hillert and M. Jarl: CALPHAD 2 (1978) 227-238.

11) M. Hillert and L.-I. Staffansson: Acta Chem. Scand. 24 (1970) 36183626.

12) H. Kaneko, T. Nishizawa and A. Chiba: J. Jpn. Inst. Metals 30 (1966) $157-163$.

13) H. H. Stadelmaier and C. B. Pollock: Z. Metallk. 60 (1969) 960-961.

14) Yu. B. Kuz'ma and V. P. Koval: Inorg. Mater. USSR 4 (1968) 381383.

15) F. N. Tavadze, K. A. Doliashvili, T. P. Lomiya and D. V. Avlokhashvili: Voprosy Metallovedeniya i Korrozii Metallov, No. 3, (Metniereva, Tbilisi 1972) pp. 12-19.

16) O. A. Bannykh, K. Enami, S. Nagasaki and A. Nishiwaki, eds., Tetsugoukin-jyoutaizu-shu (in Japanese), (AGNE Gijutsu Center, Tokyo, Japan, 2001) 189-191.

17) C. Gianoglio and C. Badini: J. Mater. Sci. 21 (1986) 4331-4334.

18) F. J. J. van Loo and J. A. van Beek: Z. Metallk. 80 (1989) 245-250.

19) K. Schwarz and P. Blaha: Comp. Mater. Sci. 28 (2003) 259-273.

20) J. P. Perdew, K. Burke and Y. Wang: Phys. Rev. B 54 (1996) 1653316539.

21) P. Villars: Pearson's Handbook: Crystallographic Data for Intermetallic Phases, (ASM International, Materials Park, OH, USA, 1997).

22) T. Furukawa: Master's Thesis, Kyushu Institute of Technology, Kitakyushu, Japan, (1999).

23) P. K. Liao and K. E. Spear: In P. Nash ed., Phase Diagrams of Binary Nickel Alloys, (ASM International, Materials Park, OH, USA, 1991) 31-36.

24) P. K. Liao and K. E. Spear: In H. Okamoto ed., Phase Diagrams of Binary Iron Alloys, (ASM International, Materials Park, OH, USA, 1993) 41-47. 